\title{
Outcome of locking plate fixation for proximal humerus fractures
}

\author{
Neil Rohra $^{1}{ }^{*}$, Jimmy Chokshi $^{1}$, Rishi Sanghavi ${ }^{2}$ \\ ${ }^{1}$ Department of Orthopedics, PS Medical College, Karamsad, India \\ ${ }^{2}$ Anand Surgical Hospital Private Limited, Naroda, Ahmedabad, India \\ Received: 04 February 2016 \\ Accepted: 27 February 2016 \\ *Correspondence: \\ Dr. Neil Rohra, \\ E-mail: drneilrohra@gmail.com \\ Copyright: () the author(s), publisher and licensee Medip Academy. This is an open-access article distributed under \\ the terms of the Creative Commons Attribution Non-Commercial License, which permits unrestricted non-commercial \\ use, distribution, and reproduction in any medium, provided the original work is properly cited.
}

\begin{abstract}
Background: The objective of the study was to evaluate functional outcome of open reduction and internal fixation with proximal humeral internal locking system (PHILOS) plate for proximal humerus fractures.

Methods: We reviewed 30 patients who underwent open reduction and internal fixation with PHILOS plate between the years 2010 to 2015 . There were 23 men and 7 women with a mean age of 36 years (range 20-64). There were 22 patients in the age group of $<60$ years and 8 patients in the age group of $>60$ years. According to Neer classification system, 12, 11 and 4 patients had2-part, 3-part, and 4-part fractures, respectively and 2 patients had 4-part fracture dislocation. All surgeries were carried out at our tertiary care trauma center. Functional evaluation of the shoulder at final follow-up was done using Neer's Evaluation Criteria.

Results: The mean follow-up period was 20 months (range 14-40 months). All fractures united clinically and radio logically. The mean time for radiological union was 13.2 weeks (range 9-26 weeks).At the final follow-up the mean Neer's Evaluation Criteria was 90 (range 76-100). The results were excellent in 17patients, Satisfactory in 8 patients, Unsatisfactory in 4 patients and Failure in 1 patient. During the follow-up, 3 cases of varus malunion, 1 case of failure of fixation were noted. No cases of AVN, hardware failure, locking screw loosening, infection or nonunion were noted.

Conclusions: PHILOS provides stable fixation in proximal humerus fractures. In order to prevent the complications like avascular necrosis, knowledge of anatomy and vascular supply of head of humerus and good surgical dissection to preserve vascularity of humeral head is important.
\end{abstract}

Keywords: Proximal humerus, PHILOS

\section{INTRODUCTION}

Proximal humerus fractures have an incidence of $5 \%$ among all the fractures. ${ }^{1}$ It is second most common upper extremity fracture, $2^{\text {nd }}$ only to distal radius fracture in patients more than 65 years. They are the third most common fracture overall following hip and distal radius fracture. ${ }^{2-6}$ High energy trauma is the cause in young adults, resulting in fracture dislocations, whereas low energy injury like simple fall while walking can be the reason in older individuals, basic reason being osteoporosis due old age; such low energy fractures can be treated conservatively.
Many different techniques have been described like closed reduction and percutaneous K-wire fixation, open reduction followed by fixation with tension band, intramedullary nails, or locking plates and prosthetic replacement. ${ }^{7-10}$ Various complications like nonunion at fracture site, avascular necrosis of head of humerus, nail migration, rotator cuff impingement syndrome, cut out of implants can occur. ${ }^{11,12}$ PHILOS have been designed to improve internal fixation in elderly patients where bones in whom bones are severely osteoporotic and help prevent complications. There is minimal soft tissue dissection and the plates provide adequate axial and angular stability. 
This study is done in order to determine the outcome of proximal humerus fracture with PHILOS plating.

\section{METHODS}

The study includes 30 patients with proximal humerus fractures treated with PHILOS plate during the period of 2010 to 2015 . Written informed consent was taken from all these patients.

\section{Inclusion criteria}

1. Closed proximal humerus fractures (2-,3-, 4-part according to Neer classification system.

2. Patients older than 18 years of age.

\section{Exclusion criteria}

1. Open fractures.

2. Pathological fractures.

3. Patients with failed conservative treatment.

There were 23 male and 7 female patients with a mean age of 36 years (range 20-64). There were 22 patients with age $<60$ years and 8 patients were in the age $>60$ years. Fracture was caused by trivial fall in 8 patients and caused by road traffic accidents and fall from height in the rest of the 22 patients. Fractures were classified based on preoperative plain radiographs. According to Neer classification system, 12, 11 and 4 patients had 2-part, 3part, and 4-part fractures, respectively and 2 patients suffered 4-part fracture dislocation. Head splitting was noted in 1 patient.

Patients were operated at our hospital under proper aseptic conditions. Patient was placed supine with a sandbag under scapula to elevate the shoulder. Proper draping was done in order to make the shoulder an upper limb properly exposed. A deltopectoral incision described by Crenshan in 1987 is made on the anterior aspect of the shoulder with exposure of the deltoid muscle. Then, the deltoid and pectoralis major muscles along with the overlying cephalic vein are identified.

With the shoulder in abducted $\left(70^{\circ}\right.$ to $\left.90^{\circ}\right)$ position, a few fibres of deltoid along with cephalic vein are retracted medially, while the rest of the deltoid is retracted laterally. This is done throughout the length of the incision.

Bone spikes are placed, one posteriorly and one superiorly to the head of the humerus. Two more spikes are placed to distal shaft anteriorly and posteriorly. This will expose the proximal humerus and the shaft of the humerus, along with the fractured site. With strict traumatic technique, very little of the periosteum is lifted to expose the underlying cortical bone so as to protect the blood supply \& to be able to anatomically reduce the fractured fragments at the surgical neck.
Proximal holes of the PHILOS plate \& the holes are drilled into the proximal humerus (head) up to the subchondral bone and are fixed with appropriate length locking screws. The other remaining holes are drilled into the shaft \& fixed with appropriate length screws (3.5mm).

The shoulder movements are confirmed clinically \& fracture reduction is confirmed on image intensifier. Wound is closed in layers with vicryl and ethilon over a drain. Wound dressing is done and then, a chest-arm strapping to provide compression and immobilization is given.

Sling \& Bandage chest-arm strapping is continued for 2 weeks. Sutures removed at the end of 2 weeks, then gentle pendulum exercises are started at the end of 2 weeks. Gentle passive flexion, abduction \& rotation exercises - after 4 weeks, check X-rays taken at 4 weeks. Active exercises after 8-10 weeks.

Post-operative evaluation was done using Neer's evaluation criteria. In a 100-point system, 35points are for pain, 25 points for range of motion (flexion, extension, abduction, internal rotation and external rotation), 30 points for function (10 activities including strength, reaching and stability) and 10 points for reconstruction of anatomy based on radiographic appearance. Mean duration of follow up was 20 months (range 14-40 months).

\section{RESULTS}

All the patients had clinical and radiological union. The mean time for radiological union was 13.2 weeks (9-26 weeks). At the final follow-up, the mean Neer's Evaluation score was 90 (76-100). The results were excellent in 17 patients, Satisfactory in 8 patients, Unsatisfactory in 4 patients and Failure in 1 patient. During the follow-up, 3 cases of varus malunion, 1 case of failure of fixation were noted. Patient with implant failure was operated with Bone grafting and replating and is healed well consequently. Remaining patients were not symptomatic enough to undergo repeat surgery. None of the patients had complications like screw loosening, implant breakage or infection.

\section{DISCUSSION}

Different techniques for the fixation of proximal humerus fractures have been described by authors. ${ }^{7-10}$ All techniques have varying rate of complications like cutout or back-out of the screws and plates, loss of fixation, fracture distal to the plate. ${ }^{13-15}$

Locking anatomical plate fixation offers many advantages compared to non-locking plates. ${ }^{15,16}$ Care must be taken to preserve the soft tissue attachment during open reduction and internal fixation since damage 
to soft tissues may decrease the vascularity of fracture fragments. ${ }^{17-19}$

In our study, we used the standard deltopectoral approach in all the patients. It is important to place the plate according to anatomy of proximal humerus, determination of Screw length with fluoroscopy, insertion of screws to the head in adequate number and position and providing medial cortical continuity prevention of varus. ${ }^{20}$ And also to fix tubercle fragments by passing sutures through the plate and rotator cuff bone junction. $^{21,22}$

In our study, overall complication rate was $20 \%$. The main complications were varus malunion in 3 patients, and fixation failure in 1 patient. Fixation failure required reoperation with bone grafting and plating.

Egol et al observed only one case of acute infection in their series of 51 patients who mainly had 3- and 4-part fractures. ${ }^{23}$ Gardner et al reported superficial wound dehiscence in one patient and Moonot et al reported one superficial infection that healed with oral antibiotic treatment. $^{18,22}$ Low incidence of infection in our study was attributed to meticulous surgical techniques and the special attention paid to soft tissue preservation.

Humeral head screw penetration $(0-23 \%)$ is noted in various studies. ${ }^{24-27}$ In our study, there is one such case. We used intraoperative fluoroscopic monitoring of the drill bit while drilling and also monitored the screw position in two views to avoid articular penetration.

In the past, incidences of AVN have been reported in a wide range, $4 \%-75 \%$ of cases. ${ }^{19,23,28-31}$ In our study we did not have a single case of AVN. However follow-up was short term. More cases of AVN could potentially arise with longer observation. ${ }^{32-34}$ Hertel and his colleagues evaluated risk factors for humeral head avascular necrosis following intracapsular proximal humerus fracture. ${ }^{35}$ They noted that most important predictor was the length of the dorsomedial metaphyseal extension $(<8 \mathrm{~mm})$, the integrity of the medial hinge (defined by greater than 2-mm shaft displacement in any direction), and fracture with an anatomic neck component (types 2, 9, 10, 11 and 12 in their binary description system). When three of these criteria were present, the positive predictive value for ischemia was $97 \%$.

Varus malunion is one of the potential complications following fixation of proximal humeral fractures. It is defined as a head shaft angle of less than 120 degrees. Moonot et al reported the incidence of malunion in 3- and 4-part proximal humeral fractures. ${ }^{22}$ Björkenheim et al reported $26.3 \%$ of the fractures having 2-, 3- and 4-part united in slightly varus position after open reduction and internal fixation with locking plate. ${ }^{22}$ Agudelo et al considered primary varus reduction to be an important risk factor which may cause poor results. ${ }^{25}$ In our study we observed $3(10 \%)$ cases of varus malunion. We did not notice nonunion and heterotopic ossification in our series.

According to Neer's evaluation criteria, excellent/good results accounted for $80.33 \%$ and only $19.67 \%$ had fair/poor results. A relatively small sample size was the main limitation of this study. In conclusion, PHILOS provides stable fixation in proximal humerus fractures. Moreover, good knowledge of anatomy and blood supply of head of humerus and appropriate dissection around shoulder joint is necessary to prevent complications like Avascular necrosis of head of humerus.

\section{CONCLUSION}

The present study of 40 patients was operated for total hip arthroplasty (THA). All the patients were operated by posterolateral approach. The combined anteversion was calculated as the sum of acetabular and femoral anteversion using a CT scan. The patients were followed up for a period of 3 months after the surgery.

From this study, the functional outcome of the patients was better when the combined anteversion was between 4-7ff as compared to the functional outcome when the combined anteversion was either less than 40 " or more than 70'. However, we required larger group of study to validate the findings.

\section{Funding: No funding sources \\ Conflict of interest: None declared}

Ethical approval: The study was approved by the Institutional Ethics Committee

\section{REFERENCES}

1. Geiger EV, Maier M, Kelm A. Functional outcome and complications following PHILOS plate fi xation in proximal humeral fractures. Acta Orthop Traumatol Turc. 2010;44(1):1-6.

2. Baron JA, Barrett JA, Karagas MR. The epidemiology of peripheral fractures. Bone. 1996;18(3 Suppl):209S-13.

3. Lanting B, MacDermid J, Drosdowech D, et al. Proximal humeral fractures: a systematic review of treatment modalities. J Shoulder Elbow Surg. 2008;17(1):42-54.

4. Lee SH, Dargent-Molina P, Breart G. Risk factors for fractures of the proximal humerus: results from the EPIDOS prospective study. J Bone Miner Res. 2002;17(5):817-25.

5. Nguyen TV, Center JR, Sambrook PN. Risk factors for proximal humerus, forearm, and wrist fractures in elderly men and women: the Dubbo Osteoporosis Epidemiology Study. Am J Epidemiol. 2001;153(6):587-95.

6. Nho SJ, Brophy RH, Barker JU, et al. Innovations in the management of displaced proximal humerus fractures. J Am Acad Orthop Surg. 2007;15(1):1226. 
7. Park MC, Murthi AM, Roth NS. Two-part and threepart fractures of the proximal humerus treated with suture fixation. J Orthop Trauma 2003;17(5):319-25.

8. Ogiwara N, Aoki M, Okamura K. Ender nailing for unstable surgical neck fractures of the humerus in elderly patients. ClinOrthopRelat Res. 1996;(330):173-80.

9. Resch H, Povacz P, Fröhlich R. Percutaneous fixation of three- and four-part fractures of the proximal humerus. J Bone Joint Surg Br. 1997;79(2):295-300.

10. Robinson CM, Page RS, Hill RM. Primary hemiarthroplasty for treatment of proximal humeral fractures. J Bone Joint Surg Am. 2003;85(7):121523.

11. Sadowski C, Riand N, Stern R. Fixation of fractures of the proximal humerus with the Plant Tan Humerus Fixator Plate: early experience with a new implant. J Shoulder Elbow Surg. 2003;12(2):148-51.

12. Björkenheim JM, Pajarinen J, Savolainen V. Internal fixation of proximal humeral fractures with a locking compression plate: a retrospective evaluation of 72 patients followed for a minimum of 1 year. Acta Orthop Scand. 2004;75(6):741-5.

13. Fankhauser F, Boldin C, Schippinger G. A new locking plate for unstable fractures of the proximal humerus. Clin Orthop Relat Res. 2005;(430):176-81.

14. Lill H, Hepp $P$, Rose $T$. The angle stable lockingproximal- humerus-plate (LPHP) for proximal humeral fractures using a small anteriorlateral-deltoid-splitting-approach technique and first results. ZentralblChir. 2004;129(1):43-8.

15. Siffri PC, Peindl RD, Coley ER. Biomechanical analysis of blade plate versus locking plate fixation for a proximal humerus fracture: comparison using cadaveric and synthetic humeri. J Orthop Trauma 2006;20(8):547-54.

16. Walsh S, Reindl R, Harvey E, et al. Biomechanical comparison of a unique locking plate versus a standard plate for internal fixation of proximal humerus fractures in a cadaveric model. ClinBiomech. 2006;21(10):1027-31.

17. Papadopoulos P, Karataglis D, Stavridis SI. Midterm results of internal fi xation of proximal humeral fractures with the PHILOS plate. Injury. 2009;40(12):1292-6.

18. Gardner MJ, Weil Y, Barker JU. The importance ofmedial support in locked plating of proximal humerus fractures. J Orthop Trauma. 2007;21(3):185-91

19. Wijgman AJ, Roolker W, Patt TW. Open reductionand internal fixation of three and four-part fractures of the proximal part of the humerus. J Bone Joint Surg. 2002;84(11):1919-25.

20. Gardner MJ, Voos JE, Wanich T, et al. Vascular implications of minimally invasive plating of proximal humerus fractures. J Orthop Trauma. 2006;20(9):602-7.
21. Liew AS, Johnson JA, Patterson SD. Effect of screw placement on fi xation in the humeral head. J Shoulder Elbow Surg. 2000;9(5):423-6.

22. Moonot P, Ashwood N, Hamlet M. Early results for treatment of three and four-part fractures of the proximal humerus using the PHILOS plate system. J Bone Joint SurgBr. 2007;89(9):1206-9.

23. Egol KA, Ong CC, Walsh M. Early complications in proximal humerus fractures (OTA Types 11) treated with locked plates. J Orthop Trauma. 2008;22(3):159-64.

24. Owsley KC, Gorczyca JT. Fracture displacement and screw cutout after open reduction and locked plate fixation ofproximal humeral fractures. J Bone Joint Surg Am. 2008;90(2):233-40.

25. Agudelo J, SchürmannM, Stahel P. Analysis of efficacy and failure in proximal humerus fractures treated with locking plates. J Orthop Trauma. 2007;21(10):676-81.

26. Koukakis A, Apostolou CD, Taneja T. Fixation of proximal humerus fractures using the PHILOS plate: early experience. Clin Orthop Relat Res. 2006;442:115-20.

27. Hepp P, Theopold J, Voigt C. The surgical approach for locking plate osteosynthesis of displaced proximal humeral fractures influences the functional outcome. J Shoulder Elbow Surg. 2008;17(1):21-8.

28. Esser RD. Treatment of three- and four-part fractures of the proximal humerus with a modified cloverleaf plate. J Orthop Trauma. 1994;8(1):15-22.

29. Lee CK, Hansen HR. Post-traumatic avascular necrosis of the humeral head in displaced proximal humeral fractures. J Trauma. 1981;21(9):788-91.

30. Gerber C, Werner CM, Vienne P. Internal fixation of complex fractures of the proximal humerus. J Bone Joint Surg Br. 2004;86(6):848-55.

31. Hawkins RJ, Bell RH, Gurr K. The three-part fracture of the proximal part of the humerus. Operative treatment. J Bone Joint Surg Am. 1986;68(9):1410-4.

32. Bastian JD, Hertel R. Initial post-fracture humeral head ischemia does not predict development of necrosis. J Shoulder Elbow Surg. 2008;17(1):2-8.

33. Gerber $\mathrm{C}$, Hersche $\mathrm{O}$, Berberat $\mathrm{C}$. The clinical relevance of post-traumatic avascular necrosis of the humeral head. J Shoulder Elbow Surg. 1998;7(6):586-90.

34. Solberg BD, Moon CN, Franco DP. Locked plating of 3- and 4-part proximal humerus fractures in older patients: the effect of initial fracture pattern on outcome. J Orthop Trauma. 2009;23(2):113-9.

35. Hertel R, Hempfing A, Stiehler M. Predictors of humeral head ischemia after intracapsular fracture of the proximalhumerus. J Shoulder Elbow Surg. 2004;13(4):427-33.

Cite this article as: Rohra N, Chokshi J, Sanghavi R. Outcome of locking plate fixation for proximal humerus fractures. Int J Res Orthop 2016;2:25-8. 